\title{
Levels of MMP-9 in patients with intracranial aneurysm: Relation with risk factors, size and clinical presentation
}

\author{
Hugo Alberto Rojas ${ }^{\mathrm{a}}$, Karla Simone da Silva Fernandes ${ }^{\mathrm{a}}$, Mariana Rodrigues Ottone ${ }^{\mathrm{a}}$, \\ Kênia Cristina S. Fonseca de Magalhães ${ }^{\mathrm{a}}$, Lucas Alverne Freitas de Albuquerque ${ }^{\mathrm{a}, \mathrm{b}}$, \\ Julio Leonardo Barbosa Pereira, ${ }^{\mathrm{a}, \mathrm{b}}$, Gerival Vieira-Júnior ${ }^{\mathrm{a}, \mathrm{b}}$, José Lopes Sousa-Filho ${ }^{\mathrm{a}, \mathrm{b}}$, \\ Bruno Silva Costa ${ }^{\mathrm{a}, \mathrm{b}}$, Valéria Cristina Sandrim ${ }^{\mathrm{c}}$, Marcos Dellaretti ${ }^{\mathrm{a}, \mathrm{b}}$, Renata Toscano Simões ${ }^{\mathrm{a}, *}$ \\ ${ }^{a}$ Institute of Education and Research of Santa Casa de Belo Horizonte Hospital - IEP/SCBH, Belo Horizonte, MG, Brazil \\ ${ }^{\mathrm{b}}$ Neurosurgery Service - Santa Casa de Belo Horizonte Hospital, Belo Horizonte, MG, Brazil \\ ${ }^{\mathrm{c}}$ Department of Pharmacology, Institute of Biosciences of Botucatu, Universidade Estadual Paulista (UNESP), São Paulo, Brazil
}

\section{A R T I C L E I N F O}

\section{Keywords:}

Metalloproteinase-9

Gelatinase-B

Intracranial aneurysm

Subarachnoid hemorrhage

\begin{abstract}
A B S T R A C T
Background: Intracranial aneurysms are arterial anomalies affecting $2 \%$ to $3 \%$ of the general population in the world and these ruptures are associated with a high mortality. Some risk factors, such as age, gender, smoking, alcohol, hypertension and familial history are associated with the number of aneurysms and their size. In addition, inflammatory processes within the blood vessels of the brain can activate matrix metalloproteinase- 9 (MMP-9), which degrades various components of the extracellular matrix, such as elastin. Thereby, this work has aimed at evaluating the relationship between plasma MMP-9 levels and the risk factors that are associated with intracranial aneurysm, as well as investigating the aneurysm statuses (ruptured and unruptured) and comparing them with the control volunteers.

Methods: Between August 2014 to June 2016, blood samples were collected from 282 patients (204 ruptured and 78 unruptured saccular intracranial aneurysms) and 286 control volunteers. The MMP-9 plasma levels were measured by ELISA. Statistical analyzes were performed with SPSS software when using parametric or nonparametric tests, after the normality tests.

Results: Higher levels of MMP-9 were found in the aneurysm groups as a whole and when they were stratified by rupture status, then compared with the control group $(\mathrm{p}<0.0001)$. When stratifying them by diameter, those smaller than $7 \mathrm{~mm}$ presented high levels of MMP-9 ( $\mathrm{p}<0.0001$ ), especially in the ruptured ones. As for risk factors, hypertension and smoking were the most important. However, hypertension was mostly associated with the ruptured aneurysms ( $\mathrm{p}<0.0001$ ).

Conclusions: High levels of MMP-9 were found in smaller ruptured and unruptured intracranial aneurysms $(<7 \mathrm{~mm})$ with strongest statistical associations than other sizes, especially when associated with smoking and hypertension.
\end{abstract}

\section{Introduction}

The main cause of a non-traumatic subarachnoid hemorrhage (SAH) is the rupture of a saccular intracranial aneurysm (IA), accounting for approximately $85 \%$ of cases [1]. Intracranial aneurysms are arterial anomalies caused by a weakening of the tunica media, which leads to a dilation in different areas of the brain vessels, mainly in the circle of Willis and in the bifurcations of the arteries [2,3]. These kinds of change affect $2 \%$ to $3 \%$ of the general population who are aged 55-60 years [4]. Other risk factors include familial history, hypertension and smoking [5].

The inflammatory processes of the cerebral vessels may induce initiation, formation, growth and the subsequent rupture of the aneurysm. This is due to an imbalance between the production and the destruction of the extracellular matrix (ECM) of vascular smooth muscle cells and the internal elastic lamina (IEL) [6]. The matrix metalloproteinase (MMP) is a family of structurally proteolytic enzymes that are zinc-dependent and that degrade various components of the ECM, such as collagen, elastin, the proteoglycans, fibronectin and laminin. They are subdivided into six groups, depending upon the components that

\footnotetext{
* Corresponding author at: Rua Domingos Vieira, 590. Santa Efigênia, CEP: 30150-240 Belo Horizonte, MG, Brazil.

E-mail address: simoesrt@yahoo.com.br (R.T. Simões).
} 
Table 1

Demographic profiles of IA and in the control group, classified by rupture status

\begin{tabular}{|c|c|c|c|c|c|c|c|}
\hline \multirow[t]{3}{*}{ Variable } & \multirow{2}{*}{\multicolumn{2}{|c|}{ Control }} & \multicolumn{4}{|c|}{ Intracranial aneurysm } & \multirow[t]{3}{*}{ p-Value } \\
\hline & & & \multicolumn{2}{|l|}{ Ruptured } & \multicolumn{2}{|c|}{ Unruptured } & \\
\hline & $\mathrm{n}=286$ & $(\%)$ & $\mathrm{n}=204$ & $(\%)$ & $\mathrm{n}=78$ & $(\%)$ & \\
\hline Age $(M \pm S D)$ & $60 \pm 10$ & - & $52 \pm 11$ & - & $52 \pm 13$ & - & $<0.05^{*}$ \\
\hline Females & 172 & $(60)$ & 153 & (75) & 59 & $(75.6)$ & $<0.05^{\#}$ \\
\hline Males & 114 & $(40)$ & 51 & (25) & 19 & $(24.4)$ & \\
\hline \multicolumn{8}{|l|}{ Smoking } \\
\hline Yes & 9 & (3) & 89 & $(43.6)$ & 22 & $(28.2)$ & $<0.05^{\&}$ \\
\hline No & 277 & (97) & 115 & $(56.4)$ & 56 & (71.8) & \\
\hline \multicolumn{8}{|l|}{ HBP } \\
\hline Yes & 150 & $(52.4)$ & 123 & $(60.3)$ & 42 & $(53.8)$ & 0.2162 \\
\hline No & 136 & $(47.6)$ & 81 & (39.7) & 36 & $(46.2)$ & \\
\hline
\end{tabular}

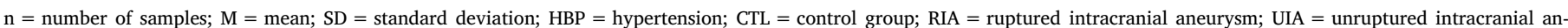
eurysm; vs. $=$ versus.

* Age: CTL $v s$ RIA $\leq 0.0001$; CTL $v s$ UIA $\leq 0.0001$; RIA $v s$ UIA $=0.9967$.

\# Gender: CTL $v s$ RIA $=0.0007$; CTL $v s$ UIA $=0.0119$; RIA $v s$ UIA $=1.000$.

\& Smoking: CTL $v s$ RIA $\leq 0.0001$; CTL $v s$ UIA $\leq 0.0001$; RIA $v s$ UIA $=0.0205$.

they degrade. Among the MMP family members that play a role in the formation and the development of intracranial aneurysms, there are the gelatinases, such as MMP-2, which degrades the collagens of Type I and Type III, as well as MMP-9 (gelatinase B), which is responsible for degrading Type 4 collagen, the proteoglycans, and elastin, being a component of the internal elastic lamina [7]. The increased blood flow induces the activation of the metalloproteinases leading to a fragmentation of the vessel wall and the subsequent rupture [8,9].

The expression of MMP-9 has been found in the blood vessels of brain aneurysms $[10,11]$, where it is produced by the inflammatory cells, especially the macrophages. The expression is mainly regulated at a transcriptional level. This is in response to several molecules, such as interleukin 1 alpha and beta (IL-1 $\alpha$ - $\beta$ ), interleukin 6 (IL-6), the transforming growth factor $\beta$ (TGF- $\beta$ ), tumor necrosis factor alpha (TNF- $\alpha$ ), the platelet-derived growth factor, and the epidermal growth factor [12].

The levels of MMP-9 play an important role in the course of ruptured and unruptured intracranial aneurysms. Some of the forms of proMMP could be released in the region of the IA wall and they persist due to the inflammatory processes, which can thus, represent a circulating molecular biomarker [12,13]. In this context, in order to evaluate if MMP-9 levels are associated with ruptured aneurysms, the aim of this study was to compare the levels of plasmatic MMP-9, between those patients who had either ruptured or unruptured intracranial aneurysms and the controls.

\section{Materials and methods}

\subsection{Patient selection and control subjects}

This work was approved by Santa Casa de Belo Horizonte Ethics Committee (CAAE: 01432312.5.0000.5138) and all the participants agreed and signed the terms of free and informed consent. In the case of unconscious patients, consent was obtained from the responsible family member. The sample was composed of patients in the Santa Casa de Belo Horizonte Hospital, Minas Gerais, Brazil. They were randomly selected and matched for age and gender, during the period of August 2014 to June 2016. The peripheral blood samples were collected from 568 volunteers: 282 patients and 286 controls. The patient group was divided into 204 subjects with ruptured intracranial aneurysms (RIA) and 78 subjects with unruptured intracranial aneurysms (UIA), displaying surgically treated saccular intracranial aneurysm, sized $<7 \mathrm{~mm}$, 7-12 mm, 13-25 mm and > $25 \mathrm{~mm}$ [14]. Smoking habits, hypertension and familial history were also considered.

\subsection{Image analyzes}

The presence of aneurysms in the patients group were confirmed by digital subtraction angiography (DSA), followed by a 3D reconstruction of the image in the pre- and postoperative period. The patients were submitted to angiography that was performed by using the transfemoral arterial approach. The angiographic examinations were performed by using a biplanar angiographic unit (Axiom Artis dBA, Siemens AG Medical Solutions, Vacuum Technology Division, Henkestraße 127 91052, Erlangen, Germany) with an image intensifier matrix of $1024 \times 1024$

\subsection{Samples collection and statistical analyzes}

The blood samples were collected in $4.5 \mathrm{~mL}$ tubes with ethylenediaminetetraacetic acid (EDTA), within a maximum period of $24 \mathrm{~h}$, after or before the arterial catheterization procedures. The plasma was separated from the total blood and it was stored at $-80^{\circ} \mathrm{C}$ until the time for analyzes. The plasma MMP-9 levels were measured by using a commercially available enzyme-linked immunosorbent assay (ELISADuoSet ELISA, DY911, R \& D Systems). All of the samples were run in duplicate and the MMP-9 quantification was determined when using the standard curve analysis method. Statistical analyzes were performed with IBM SPSS Statistics Software Version 20, using parametric or non-parametric tests, after normal distribution analyzes. All the statistical tests were performed by using a significance level of $<0.05$.

\section{Results}

\subsection{Demographic profiles of the patients and the controls}

The groups analyzed in this study presented similar profiles of age, gender and hypertension. However, smoking habits were very low in the control group (3\%). All of the data is shown in Table 1.

\subsection{MMP-9 plasma levels in the patients and in the controls}

The MMP-9 quantification of the subjects revealed that the MMP-9 plasmatic levels were higher in the patient groups than they were in the control group $(190.5 \pm 5.4$ and $149.7 \pm 4.7 ; p<0.0001)$. The differences remained when the aneurysms were stratified into ruptured and unruptured statuses and then compared again with the control group ( $\mathrm{p}<0.0001$ and $\mathrm{p}<0.0006$, respectively). However, when in comparison between the intracranial aneurysm groups (RIA vs. UIA), no statistical differences were observed $(\mathrm{p}=0.4792)$. 
Table 2

Plasma MMP-9 levels in the patients with IA and in the control group, classified according to the diameters.

\begin{tabular}{|c|c|c|c|c|c|c|}
\hline \multirow[t]{2}{*}{ Groups } & \multicolumn{4}{|c|}{ Diameter of intracranial aneurysms (mm) } & \multirow[t]{3}{*}{ Group association } & \multirow[t]{3}{*}{ p-Value } \\
\hline & $<7$ & $7-12$ & $12-25$ & $>25$ & & \\
\hline MMP-9 Levels & $M \pm S E$ & $\mathrm{M} \pm \mathrm{SE}$ & $\mathrm{M} \pm \mathrm{SE}$ & $M \pm S E$ & & \\
\hline IA $(n=268)^{a}$ & $192.5 \pm 7.33(n=138)$ & $188.1 \pm 11.12(\mathrm{n}=82)$ & $198.6 \pm 17.25(\mathrm{n}=34)$ & $194.2 \pm 20.74(\mathrm{n}=14)$ & $\begin{array}{l}\text { IA vs. CTL } \\
<7 \text { vs. CTL } \\
7-12 \text { vs. CTL } \\
12-25 \text { vs. CTL } \\
>25 \text { vs. CTL }\end{array}$ & $\begin{array}{l}<0.0001 \\
<0.0001 \\
0.0029 \\
0.0053 \\
0.0228\end{array}$ \\
\hline Ruptured $(\mathrm{n}=193)^{\mathrm{b}}$ & $191.4 \pm 8.3(n=104)$ & $189.9 \pm 13.31(n=60)$ & $200.8 \pm 24.18(n=23)$ & $207.7 \pm 30.1(n=6)$ & $\begin{array}{l}\text { RIA vs. CTL } \\
<7 \text { vs. CTL } \\
7-12 \text { vs. CTL } \\
12-25 \text { vs. CTL } \\
>25 \text { vs. CTL }\end{array}$ & $\begin{array}{l}<0.0001 \\
<0.0001 \\
0.0083 \\
0.0621 \\
0.0470\end{array}$ \\
\hline Unruptured $(\mathrm{n}=75)^{\mathrm{c}}$ & $191.1 \pm 16.29(\mathrm{n}=32)$ & $180.9 \pm 20.01(n=22)$ & $181.3 \pm 18.14(n=13)$ & $184.0 \pm 29.66(n=8)$ & $\begin{array}{l}\text { UIA vs. CTL } \\
<7 \text { vs. CTL } \\
7-12 \text { vs. CTL } \\
12-25 \text { vs. CTL } \\
>25 \text { vs. CTL }\end{array}$ & $\begin{array}{l}0.0108 \\
0.0071 \\
0.1082 \\
0.0578 \\
0.1848\end{array}$ \\
\hline CTL (286) & $149.7 \pm 4.75$ & - & - & - & - & - \\
\hline
\end{tabular}

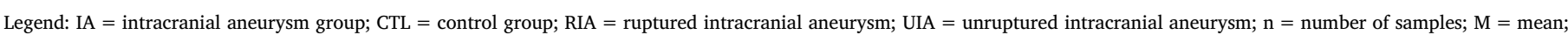
$\mathrm{SE}=$ standard error; $^{\mathrm{a}}=$ no diameter information of 14 patients $\left({ }^{\mathrm{b}}=11\right.$ RIA and ${ }^{\mathrm{c}}=3$ UIA $) ;$ vs. $=$ versus.

\subsection{Diameters of the intracranial aneurysms and the plasma levels of MMP-}

When considering the diameters of the aneurysms, no significant differences were observed in the MMP-9 levels within the group of IAs as a whole $(<7 \mathrm{~mm}, 7-12 \mathrm{~mm}, 12-25 \mathrm{~mm}$ and $>25 \mathrm{~mm})$ or when stratified into the RIA and UIA sections. Several statistical associations were only found when the groups were compared with the control group ( $\mathrm{p}<0.05$ ) (Table 2). No statistical significances were found when the plasma levels were compared between the diameters of the ruptured aneurysms and the unruptured aneurysms. However, a slight increase in the MMP-9 levels was observed in the ruptured aneurysm group $>12 \mathrm{~mm}$, when compared with the unruptured aneurysms, but without any statistical significance. All of the results are shown in Table 2.

\subsection{MMP-9 and risk factors}

Smoking, hypertension and familial history were evaluated as being risk factors for the development and the rupture of the intracranial aneurysms. Differential levels of MMP-9 were observed among the RIA patients, with and without hypertension $(p=0.0314)$. However, this association was stronger when the RIA hypertensions were compared with the controls, with and without hypertension $(p<0.0001$ ). Smoking also showed a significant association with the aneurysms when compared with the non-smoking controls $(\mathrm{p}<.0001)$. However, due to the low number of smoking controls, this data loses some strength.

No associations were found within familial history. The results are shown in Table 3.

The levels of MMP-9 were also measured in single and multiple aneurysms as a whole, as well as in the stratified ruptured and unruptured aneurysm groups. No statistical associations were found (data not show).

\section{Discussion}

\subsection{MMP-9 levels in the ruptured and unruptured intracranial aneurysms}

Intracranial aneurysms are multifactorial diseases and they include a neuroinflammation state that may be induced, among other factors, by the MMP expression. The MMPs, mainly MMP-2 and MMP-9, degrade the extracellular matrix and disrupt the tight junction proteins (TJP), leading to aneurysm development and rupture [13]. According to this data, the aim of this study was to analyze the MMP-9 plasma expression in those patients with IA that had ruptured or unruptured aneurysms, together with the controls. The results have demonstrated that the MMP-9 plasma concentrations were differentially expressed between those patients with IAs (as a whole and then stratified into ruptured and unruptured) and the control group, whereby the groups with IA had significantly higher levels of MMP-9. However, these levels were not strong enough to define the risk of rupture when the RIAs and the UIAs were compared, maybe due to the small number of UIAs $(n=78)$, when in relation to the ruptured aneurysms $(n=204)$. This was a limiting factor that we could not control, since most of the patients seen in a public service like ours, already arrive with ruptured aneurysms. Even though the study found no association between the MMP-9 levels and the rupture risk of aneurysms in these samples, the results have corroborated with those described by Peng et al. [15], who showed high levels of MMP-9 in the ruptured and unruptured aneurysms when they compared them with control [15]. Other studies have also found differing MMP-9 plasma levels, but only between the ruptured aneurysms and control, with all of them having a smaller sample than the current one $[7,10,11,16]$.

\subsection{Plasmatic levels of MMP-9 according to the diameter of the aneurysm}

This study was also interested in verifying if the high levels of MMP9 that had been found in the aneurysm groups could influence the aneurysm size ( $<7 \mathrm{~mm}, 7-12 \mathrm{~mm} ; 12-25 \mathrm{~mm}$ and $>25 \mathrm{~mm}$ ). Most of the patients had small IAs, $<7 \mathrm{~mm}(51.5 \%)$, followed by $7-12 \mathrm{~mm}$ IAs (30.6\%). The same proportions were also observed when the IAs were divided into ruptured (54\% and $31 \%$, respectively) and unruptured ( $42.6 \%$ and $29.3 \%$, respectively).

As in other results, in our samples, strong associations were only found when the sizes were compared with the control group. Ruptured IAs $<7 \mathrm{~mm}$ had especially powerful statistical associations $(<0.0001)$. On the other hand, it was possible to observe that those in the RIA group $>12 \mathrm{~mm}$ had slightly higher levels of MMP-9 than did the UIA group, but the small number of patients with this particular IA size did not show significant results. These results are in accordance with those described by other researchers [17-20]. In a big study with 889 patients 
Table 3

Plasma levels of MMP-9 and the risk factors in the ruptured and unruptured intracranial aneurysms.

\begin{tabular}{|c|c|c|c|c|c|c|c|c|c|c|}
\hline \multirow[t]{3}{*}{ Risk factors } & \multicolumn{4}{|c|}{ Aneurysm group } & \multicolumn{2}{|l|}{ Control } & \multicolumn{3}{|c|}{ Group association } & \multirow[t]{3}{*}{$\mathrm{p}$-Value } \\
\hline & \multirow[t]{2}{*}{ (n) } & RIA & \multirow[t]{2}{*}{ (n) } & UIA & \multirow[t]{2}{*}{ (n) } & & & & & \\
\hline & & $\mathrm{M} \pm \mathrm{SE}$ & & $\mathrm{M} \pm \mathrm{SE}$ & & $\mathrm{M} \pm \mathrm{SE}$ & & & & \\
\hline \multicolumn{11}{|l|}{ Smoking } \\
\hline & & & & & & & RIA SMK & vs. & CTL No SMK & $<0.0001$ \\
\hline Yes & (89) & $191.6 \pm 10.03$ & $(22)$ & $200.2 \pm 16.51$ & (9) & $172.5 \pm 18.21$ & RIA No SMK & $v s$. & CTL No SMK & $<0.0001$ \\
\hline \multirow[t]{2}{*}{ No } & (115) & $194.6 \pm 8.61$ & $(56)$ & $176.8 \pm 11.82$ & (277) & $149 \pm 4.87$ & UIA No SMK & vs. & CTL No SMK & 0.0146 \\
\hline & & & & & & & UIA SMK & $v s$. & CTL No SMK & 0.0018 \\
\hline Total & 204 & & 78 & & 286 & & & & & \\
\hline \multicolumn{11}{|l|}{ HBP } \\
\hline & & & & & & & RIA HBP & $v s$. & RIA No HBP & 0.0314 \\
\hline & & & & & & & RIA HBP & $v s$. & CTL HBP & $<0.0001$ \\
\hline Yes & (123) & $205.3 \pm 8.65$ & $(42)$ & $186 \pm 12.19$ & $(150)$ & $153.5 \pm 6.79$ & RIA HBP & $v s$. & CTL No HBP & $<0.0001$ \\
\hline \multirow[t]{3}{*}{ No } & $(81)$ & $175 \pm 9.56$ & (36) & $180.3 \pm 15.64$ & $(136)$ & $145.5 \pm 6.62$ & UIA HBP & $v s$. & CTL HBP & 0.0082 \\
\hline & & & & & & & UIA HBP & $v s$. & CTL No HBP & 0.0019 \\
\hline & & & & & & & UIA No HBP & vs. & CTL No HBP & 0.0365 \\
\hline Total & 204 & & 78 & & 286 & & & & & \\
\hline \multicolumn{11}{|l|}{ F. history } \\
\hline Yes & (29) & $188 \pm 18.35$ & (11) & $169 \pm 25.53$ & - & - & - & - & - & 0.5812 \\
\hline No & (175) & $194.1 \pm 6.7$ & (67) & $187.8 \pm 10.64$ & - & - & - & - & - & 0.6516 \\
\hline Total & 204 & & 78 & & 286 & & & & & \\
\hline
\end{tabular}

Legend: $\mathrm{n}=$ number of samples; $\mathrm{M}=$ mean; $\mathrm{SE}=$ standard error; SMK = smoking; $\mathrm{HBP}=$ hypertension; $\mathrm{F}$. history $=$ familial history; $v s .=$ versus

with RIA $(n=627)$ and UIA $(n=262)$, Joo et al. [21] found that $71.8 \%$ of the RIAs were smaller than $7 \mathrm{~mm}$ in diameter and that $87.9 \%$ were smaller than $10 \mathrm{~mm}$ [21]. Bijlenga et al. [23] and Orz and AlYamany [22] also reported that aneurysms $<7 \mathrm{~mm}$ had a higher risk of rupture, especially those located in the anterior cerebral arteries [22,23], which was also observed in our results. Freytag [20], Kassell and Torner [19] and Ohashi et al. [18] reported that a major part of the RIAs were between $5 \mathrm{~mm}$ and $10 \mathrm{~mm}$ [18-20] and Dolati P. et al. [24] when studying 123 patients with RIA, reported that $37 \%$ had diameters $<5 \mathrm{~mm}$ [24].

In an interesting review of cases between 1966 and 2009, Chmayssani et al. [25] found that $47 \%$ of UIAs $\leq 7 \mathrm{~mm}$ evolved into rupture, some of them after growth and others directly [25]. Żyłkowski et al. [26], when calculating the annual risk of growth of unruptured aneurysms $<7 \mathrm{~mm}$ estimated that overall, $2.55 \%$ evolved into rupture [26]. On the other hand, in a study by Chyatte D. et al. [11], where they evaluated the activity of MMP-9 in the plasma of 31 patients with RIA and UIA, as well as in 14 controls, no statistical associations were found in the different diameters of aneurysms [25]. However, significant results have been shown when comparing the high and low MMP-9 enzymatic activities in patients with IA versus controls [11].

Although there is no agreement in the clinical management of which size of aneurysm to operate on, in order to prevent rupture, the data of the present study agrees with others that show that a significant number of aneurysms $<7 \mathrm{~mm}$ may rupture, which can justify a closer follow-up, especially when they are located in the anterior cerebral arteries.

Another interesting finding that was observed in this study was that the MMP-9 levels in the UIAs were higher in those aneurysms that were $<7 \mathrm{~mm}$. However, a small reduction and a stabilization of these levels was observed, according to the diameter that the aneurysm increased. On the other hand, in the RIAs, the levels of MMP-9 tended to increase with the diameter of the aneurysm. Unfortunately, this data did not show statistical significance.

\section{3. $M M P-9$ and risk factors}

The physiology of brain vessels can be modified in the pathological process, probably by a combination of the hemodynamical factors, such as the modifiable factors (smoking, alcoholism) and the non-modifiable factors (hypertension, gender, age, etc.) of each patient. These factors can lead to the production of proteins by the brain cells (including MMP-9) and that they will act directly on the thickness of the tunica media, causing structural defects of the IAs and resulting in their rupture [27]. In this work, the levels of MMP-9 were higher in the smoking patients, than in the non-smoking controls $(193.3 \pm 8.65$ vs. $149 \pm 4.87)$. In the patients with ruptured aneurysms, significant associations were also observed in both the smoking and the non-smoking patients, especially when compared with the non-smoking controls (191.6 $\pm 10.03 ; 194.6 \pm 8.61$ vs. $149 \pm 4.87$, respectively). In addition, it was the same when the smoking UIAs were compared with the non-smoking controls $(200.2 \pm 16.51$ vs. $149 \pm 4.87)$. According to Vikman [28], the effects of MMP-9, in response to the inflammatory processes in the cerebral blood vessels, after being exposed to cigar particles, increased the MMP-9 expression in the aneurysms [28]. It has been shown that smoking significantly increased the risk of both the aneurysm formation and the rupture and that the ratio for RIA:UIA was 2.4:1.7 $[29,30]$. There is possibly a gene-environment interaction in the RIAs, where smoking may be influencing the MMP-9 gene expression $[28,31]$. The high MMP activities could perhaps explain the higher incidence of SAH in the smokers. This is possibly due to the loss of the internal elastic lamina, the thinning of the media and the formation of the aneurysm, resulting in a degradation of the extracellular matrix, leading to rupture of the aneurysm [32].

Another important risk factor for the development and the rupture of aneurysms is hypertension. The sudden and short-term increment in blood pressure that is caused by daily activities is a relevant pathway for the biogenesis of a ruptured aneurysm [33,34]. This is since the cerebral artery does not have an external elastic lamina and the adventitia layer then develops into a weaker and becomes less resistant to stress [35].

In the present study, in all of the comparisons, the MMP-9 levels were significantly higher in the hypertensive patients, even when compared the aneurysm groups, with and without hypertension $(200.4 \pm 7.12$ vs. $176.6 \pm 8.15)$. However, the association was stronger when the hypertensive IA patients were compared with the control group, either with or without hypertension (both $p<0.0001$ ). The same significant result was observed when comparing RIA HYP with RIA No HBP ( $\mathrm{p}=0.0314)$, as well as when making comparisons with the control group ( $p<0.0001$ ). The UIAs also showed significant 
levels, but only when compared with the control group, being hypertensive or not $(\mathrm{p}<0.05)$. The influences of MMP-9 and hypertension in the rupture of aneurysms has been shown by Nuki et al. [36] in mice models that have a similar histology to those reported in human intracranial aneurysms. They observed that the incidence of intracranial aneurysms was reduced to $40 \%$ in the hypertensive MMP-9 knockout mice when compared to the wild type mice, suggesting an important role of this gelatinase in aneurysm formation and rupture [36]. Hemodynamical stress could degenerate the internal elastic lamina due to the inflammatory processes, with a destruction of the tight junctions, which could then facilitate the migration of the macrophages and the formation and rupture of cerebral aneurysms [37].

Makino et al. [38] used the same characteristics and they found that the induction of hypertension resulted in the formation and the rupture of the aneurysms (SAH) that were detected through neurological symptoms. They found that in the brain tissue samples, there were MMP-9 activities in the unruptured aneurysms and there were abundant MMP-9 activities in the ruptured aneurysms [38].

In a human study (2007), the MMP expression levels have been shown to be significantly higher in the serum of those patients with ruptured aneurysms (SAH) with hypertension, when compared to those with unruptured aneurysms [39]. This data is similar to our study, demonstrating that the activities and the expression of MMP-9 are more relevant in the damage of the vascular extracellular matrix in hypertensive individuals. However, other studies have reported that hypertension may play a more important role in the formation of the aneurysm than in its rupture, including the formation of new aneurysms after the treatment of an RIA [40].

Interestingly, in our samples, different levels of MMP-9 were observed in the RIAs between those with and without hypertension. However, the same profile was not observed between the smokers, suggesting that hypertension is an important factor for the RIAs.

\section{Conclusions}

In this study, it was observed that smoking increased the levels of MMP-9 in those patients with an RIA and a UIA. However, this association was not as strongly associated with ruptured aneurysms as hypertension. On the other hand, high levels of MMP-9 were found in smaller ruptured and unruptured intracranial aneurysms $(<7 \mathrm{~mm})$ with strongest statistical associations than other sizes, suggesting that these patients should be followed closely, especially if associated with hypertension.

\section{Acknowledgements}

The authors would like to thank the volunteers for the samples, together with all of the neurosurgery team of Santa Casa de Belo Horizonte Hospital, Minas Gerais, Brazil, for their technical support. We also thank CAPES (Doctoral Grant PEC-PG $n^{\circ} 15138127$ ) and FAPEMIG (APQ-02010-14) for their financial support.

\section{Reference}

[1] J. van Gijn, G.J. Rinkel, Subarachnoid haemorrhage: diagnosis, causes and management, Brain 124 (Pt 2) (2001) 249-278.

[2] J.M. Alfano, J. Kolega, S.K. Natarajan, J. Xiang, R.A. Paluch, E.I. Levy, et al., Intracranial aneurysms occur more frequently at bifurcation sites that typically experience higher hemodynamic stresses, Neurosurgery 73 (3) (2013) 497-505.

[3] B.S. Carter, S. Sheth, E. Chang, M. Sethl, C.S. Ogilvy, Epidemiology of the size distribution of intracranial bifurcation aneurysms: smaller size of distal aneurysms and increasing size of unruptured aneurysms with age, Neurosurgery 58 (2) (2006) 217-223 (discussion -23).

[4] L.N. Williams, R.D. Brown, Management of unruptured intracranial aneurysms, Neurol. Clin. Pract. 3 (2) (2013) 99-108.

[5] M.H.M. Vlak, G.J.E. Rinkel, P. Greebe, A. Algra, Independent risk factors for intracranial aneurysms and their joint effect: a case-control study, Stroke 44 (4) (2013) 984-987.

[6] B.E.S. Taylor, G. Appelboom, R. Zilinyi, A. Goodman, D. Chapel, M. LoPresti, et al.,
Role of the complement cascade in cerebral aneurysm formation, growth, and rupture, Neuroimmunol. Neuroinflamm. 2 (2) (2015) 93-101.

[7] D.L. Penn, S.R. Witte, R.J. Komotar, E. Sander Connolly Jr., The role of vascular remodeling and inflammation in the pathogenesis of intracranial aneurysms, J. Clin. Neurosci. 21 (1) (2014) 28-32.

[8] J. Kolega, L. Gao, M. Mandelbaum, J. Mocco, A.H. Siddiqui, S.K. Natarajan, et al., Cellular and molecular responses of the basilar terminus to hemodynamics during intracranial aneurysm initiation in a rabbit model, J. Vasc. Res. 48 (5) (2011) $429-442$.

[9] F. Tronc, Z. Mallat, S. Lehoux, M. Wassef, B. Esposito, A. Tedgui, Role of matrix metalloproteinases in blood flow-induced arterial enlargement: interaction with NO, Arterioscler. Thromb. Vasc. Biol. 20 (12) (2000) E120-6.

[10] S.C. Kim, M. Singh, J. Huang, C.J. Prestigiacomo, C.J. Winfree, R.A. Solomon, et al, Matrix metalloproteinase-9 in cerebral aneurysms, Neurosurgery 41 (3) (1997) 642-666 (discussion 6-7).

[11] D. Chyatte, I. Lewis, Gelatinase activity and the occurrence of cerebral aneurysms, Stroke 28 (4) (1997) 799-804.

[12] P.E. Van den Steen, B. Dubois, I. Nelissen, P.M. Rudd, R.A. Dwek, G. Opdenakker, Biochemistry and molecular biology of gelatinase B or matrix metalloproteinase- 9 (MMP-9), Crit. Rev. Biochem. Mol. Biol. 37 (6) (2002) 375-536.

[13] R.G. Rempe, A.M. Hartz, B. Bauer, Matrix metalloproteinases in the brain and blood-brain barrier: versatile breakers and makers, J. Cereb. Blood Flow Metab. 36 (9) (2016) 1481-1507.

[14] D.O. Wiebers, J.P. Whisnant, J. Huston 3rd, I. Meissner, R.D. Brown Jr. D.G. Piepgras, et al., Unruptured intracranial aneurysms: natural history, clinical outcome, and risks of surgical and endovascular treatment, Lancet 362 (9378) (2003) 103-110.

[15] Y.-T. Peng, X.-E. Shi, Z.-Q. Li, X. He, Y.-M. Sun, Particularly interesting Cys-his-rich protein is highly expressed in human intracranial aneurysms and resists aneurysmal rupture, Exp. Ther. Med. 12 (6) (2016) 3905-3912.

[16] S. Horstmann, Y. Su, J. Koziol, U. Meyding-Lamade, S. Nagel, S. Wagner, MMP-2 and MMP-9 levels in peripheral blood after subarachnoid hemorrhage, J. Neurol. Sci. 251 (1-2) (2006) 82-86.

[17] M. Yonekura, Small unruptured aneurysm verification (SUAVe Study, Japan)—interim report, Neurol. Med. Chir. 44 (4) (2004) 213-214.

[18] Y. Ohashi, T. Horikoshi, M. Sugita, T. Yagishita, H. Nukui, Size of cerebral aneurysms and related factors in patients with subarachnoid hemorrhage, Surg. Neurol. 61 (3) (2004) 239-245 (discussion 45-7).

[19] N.F. Kassell, J.C. Torner, Size of intracranial aneurysms, Neurosurgery 12 (3) (1983) 291-297.

[20] E. Freytag, Fatal rupture of intracranial aneurysms. Survey of 250 medicolegal cases, Arch. Pathol. 81 (5) (1966) 418-424.

[21] S.W. Joo, S.I. Lee, S.J. Noh, Y.G. Jeong, M.S. Kim, Y.T. Jeong, What is the significance of a large number of ruptured aneurysms smaller than $7 \mathrm{~mm}$ in diameter? J. Korean Neurosurg. Soc. 45 (2) (2009) 85-89.

[22] Y. Orz, M. AlYamany, The impact of size and location on rupture of intracranial aneurysms, Asian J. Neurosurg. 10 (1) (2015) 26-31.

[23] P. Bijlenga, C. Ebeling, M. Jaegersberg, P. Summers, A. Rogers, A. Waterworth, et al., Risk of rupture of small anterior communicating artery aneurysms is similar to posterior circulation aneurysms, Stroke 44 (11) (2013) 3018-3026.

[24] P. Dolati, D. Pittman, W.F. Morrish, J. Wong, G.R. Sutherland, The frequency of subarachnoid hemorrhage from very small cerebral aneurysms $(<5 \mathrm{~mm})$ : a population-based study, Cureus 7 (6) (2015) e279.

[25] M. Chmayssani, J.G. Rebeiz, T.J. Rebeiz, H.H. Batjer, B.R. Bendok, Relationship of growth to aneurysm rupture in asymptomatic aneurysms $\leq 7 \mathrm{~mm}$ : a systematic analysis of the literature, Neurosurgery 68 (5) (2011) 1164-1171 (discussion 71).

[26] J. Żyłkowski, P. Kunert, M. Jaworski, G. Rosiak, A. Marchel, O. Rowiński, Changes of size and shape of small, unruptured intracranial aneurysms in repeated computed tomography angiography studies, Videosurg. Other Miniinvasive Techniques 10 (2) (2015) 178-188.

[27] W.M. Ho, C.M. Chen, Y.S. Lee, K.H. Chang, H.W. Chen, S.T. Chen, et al., Association of MMP-9 haplotypes and TIMP-1 polymorphism with spontaneous deep intracerebral hemorrhage in the Taiwan population, PLoS One 10 (5) (2015) e0125397.

[28] P. Vikman, C.-B. Xu, L. Edvinsson, Lipid-soluble cigarette smoking particles induce expression of inflammatory and extracellular-matrix-related genes in rat cerebral arteries, Vasc. Health Risk Manag. 5 (2009) 333-341.

[29] K. Matsumoto, K. Akagi, M. Abekura, M. Ohkawa, O. Tasaki, S. Oshino, Cigarette smoking increases the risk of developing a cerebral aneurysm and of subarachnoid hemorrhage, No Shinkei Geka 27 (9) (1999) 831-835.

[30] E.S. Connolly Jr., A. Poisik, C.J. Winfree, L.J. Kim, J. Huang, D.J. McMahon, et al., Cigarette smoking and the development and rupture of cerebral aneurysms in a mixed race population: implications for population screening and smoking cessation, J. Stroke Cerebrovasc. Dis 8 (4) (1999) 248-253.

[31] D. Woo, J. Khoury, M.M. Haverbusch, P. Sekar, M.L. Flaherty, D.O. Kleindorfer, et al., Smoking and family history and risk of aneurysmal subarachnoid hemorrhage, Neurology 72 (1) (2009) 69-72.

[32] N. Chalouhi, M.S. Ali, P.M. Jabbour, S.I. Tjoumakaris, L.F. Gonzalez, R.H. Rosenwasser, et al., Biology of intracranial aneurysms: role of inflammation, J Cereb. Blood Flow Metab. 32 (9) (2012) 1659-1676.

[33] M.H. Vlak, G.J. Rinkel, P. Greebe, J.G. van der Bom, A. Algra, Trigger factors and their attributable risk for rupture of intracranial aneurysms: a case-crossover study, Stroke 42 (7) (2011) 1878-1882.

[34] B.V. Nahed, M.L. DiLuna, T. Morgan, E. Ocal, A.A. Hawkins, K. Ozduman, et al., Hypertension, age, and location predict rupture of small intracranial aneurysms, Neurosurgery 57 (4) (2005) 676-683 (discussion -83). 
[35] E.I. Gaal, P. Salo, K. Kristiansson, K. Rehnstrom, J. Kettunen, A.P. Sarin, et al., Intracranial aneurysm risk locus $5 q 23.2$ is associated with elevated systolic blood pressure, PLoS Genet. 8 (3) (2012) e1002563.

[36] Y. Nuki, T.-L. Tsou, C. Kurihara, M. Kanematsu, Y. Kanematsu, T. Hashimoto, Elastase-induced intracranial aneurysms in hypertensive mice, Hypertension 54 (6) (2009) 1337-1344.

[37] Y. Tada, K. Yagi, K.T. Kitazato, T. Tamura, T. Kinouchi, K. Shimada, et al., Reduction of endothelial tight junction proteins is related to cerebral aneurysm formation in rats, J. Hypertens. 28 (9) (2010) 1883-1891.
[38] H. Makino, Y. Tada, K. Wada, E.I. Liang, M. Chang, S. Mobashery, et al., Pharmacological stabilization of intracranial aneurysms in mice: a feasibility study, Stroke 43 (9) (2012) 2450-2456.

[39] D. Jin, J. Sheng, X. Yang, B. Gao, Matrix metalloproteinases and tissue inhibitors of metalloproteinases expression in human cerebral ruptured and unruptured aneurysm, Surg. Neurol. 68 (Suppl. 2) (2007) S11-6 (discussion S6).

[40] R.M. Starke, N. Chalouhi, M.S. Ali, P.M. Jabbour, S.I. Tjoumakaris, L.F. Gonzalez, et al., The role of oxidative stress in cerebral aneurysm formation and rupture, Curr. Neurovasc. Res. 10 (3) (2013) 247-255. 